\title{
Article \\ Rheological Properties of MWCNT-Doped Titanium-Oxo-Alkoxide Gel Materials for Fiber Drawing
}

\author{
Tanel Tätte ${ }^{1, *}$, Medhat Hussainov ${ }^{2}$, Mahsa Amiri ${ }^{1}$, Alexander Vanetsev ${ }^{1} \mathbb{D}$, Madis Paalo ${ }^{1}$ \\ and Irina Hussainova 2 (D) \\ 1 Institute of Physics, University of Tartu, Riia 142, 51014 Tartu, Estonia; mahsa.amiri@ut.ee (M.A.); \\ alexander.vanetsev@ut.ee (A.V.); madis.paalo@fi.tartu.ee (M.P.) \\ 2 School of Engineering, Department of Mechanical and Industrial Engineering, Tallinn University of Technology, \\ Ehitajate tee 5, 19086 Tallinn, Estonia; medhat.hussainov@taltech.ee (M.H.); irina.hussainova@ttu.ee (I.H.) \\ * Correspondence: tanel.tatte@ut.ee
}

check for updates

Citation: Tätte, T.; Hussainov, M.; Amiri, M.; Vanetsev, A.; Paalo, M. Hussainova, I. Rheological Properties of MWCNT-Doped Titanium-Oxo -Alkoxide Gel Materials for Fiber Drawing. Materials 2022, 15, 1186 https://doi.org/10.3390/ ma15031186

Academic Editor: Ramón Pamies

Received: 30 December 2021

Accepted: 26 January 2022

Published: 4 February 2022

Publisher's Note: MDPI stays neutral with regard to jurisdictional claims in published maps and institutional affiliations.

Copyright: (C) 2022 by the authors. Licensee MDPI, Basel, Switzerland. This article is an open access article distributed under the terms and conditions of the Creative Commons Attribution (CC BY) license (https:// creativecommons.org/licenses/by/ $4.0 /)$.

\begin{abstract}
A strategy of doping by multi-walled carbon nanotubes (MWCNT) to enhance mechanical strength and the electrical conductivity of ceramic fibers has nowadays attracted a great deal of attention for a wide variety of industrial applications. This study focuses on the effect of MWCNTs on rheological properties of metal alkoxide precursors used for the preparation of nanoceramic metal oxide fibers. The rheological behavior of MWCNT-loaded titanium alkoxide sol precursors has been evaluated via an extensional rheometry method. A substantial decrease in elongational viscosity and relaxation time has been observed upon an introduction of MWCNTs even of low concentrations (less than $0.1 \mathrm{wt} . \%$ ). A high quality MWCNT/nanoceramic $\mathrm{TiO}_{2}$ composite fibers drawn from the specified precursors has been validated. The MWCNT percolation, which is mandatory for electrical conductivity $(50 \mathrm{~S} / \mathrm{m})$, has been achieved at $1 \mathrm{wt} . \%$ MWCNT doping.
\end{abstract}

Keywords: CNT doped composites; titanium oxide; sol-gel; rheology; elongational viscosity

\section{Introduction}

Carbon nanotubes (CNT) of superior mechanical, electrical, and thermal properties [1-4] are frequently used in order to enhance the properties of a wide variety of materials, for example, ceramics and/or ceramic matrix composites (CMCs). The CNT added composites combine synergistic effects of their components. The addition of CNTs to the brittle $\mathrm{Al}_{2} \mathrm{O}_{3}$ enhances its toughness significantly, preserving a high-temperature stability and exceptional creep resistance [5]. Similarly, electrical conductivity of thermally and chemically highly stable but inherently dielectric $\mathrm{TiO}_{2}$ can be boosted enough for application of $\mathrm{TiO}_{2}$ as long-cycle-life anodes in the lithium-ion batteries [6,7].

One of the key challenges in the preparation of the reinforced composites is the uniform dispersion of CNTs in the matrix. Agglomeration and non-homogeneous distribution of nanotubes act as defects promoting stress-concentration and failure of materials [8]. Numerous techniques have been proposed to fabricate CNT-reinforced ceramic composites including chemical vapor decomposition (CVD) [9], plasma sintering [10], colloidal processing [11], electrophoretic deposition [12], sol-gel [13], etc. In principle, the methods can be classified as top-down and bottom-up approaches. The first approach is based on applying shear forces to distribute CNTs throughout preliminarily prepared matrix precursors, ultrasonic probes, ball milling, etc. In case of the bottom-up approach, for example, the sol-gel method, two constituents are mixed at the molecular level [14,15]. Solid composites with a desired structure are obtained as a result of gelation of an initial sol matrix, which is typically prepared from metal alkoxides [16]. From the point of view of the final product homogeneity, the bottom-up approaches are more anticipated as they allow homogenous dispersion of CNTs and better adhesion between CNTs and precursor particles. Besides, a sol-gel procedure offers a simple method for giving a final shape for the materials at a room 
temperature. During the sol-gel transition, the viscosity of sol-material increases until the material transforms elastic gels as a result of formation of a 3D gel network over the whole volume $[17,18]$.

Previously we have demonstrated that chemical reactions of alkoxides of different metals proceed with significantly different kinetics [19]. For example, gelation of titanium butoxide sols occurs much more homogeneously with the formation of Van der Waals bonds in the beginning of process as compared to zirconium butoxide sols, which immediately lose a majority of alkoxy groups in a contact with water, therefore releasing a significant amount of alkoxy groups and forming strong covalent bonds between the metal-oxo-alkoxy sol particles. It also was demonstrated that, due to the large quantity of released alcohol, sol particles are free to rearrange and self-form into high quality $\mathrm{ZrO}_{2}$ gel microtubes with optical wave guiding properties [20].

Viscosity and rheological properties of sols and forming gels depend on the structure and can therefore be used to monitor the formation process and condition of the final gel materials [21,22]. Rheological study of sol materials is of a great importance for the controllable preparation of composites [23-26] In the wake of this research direction, it was found that sols and dispersions of nano objects in the liquid phase can change rheological characteristics of the latter in rather different ways depending on the chemical nature and geometry of both the liquid and the nanophase. Hammat et al. [27] have obtained Newtonian nanofluids with 2 wt.\% concentration of $\mathrm{Mg}(\mathrm{OH})_{2}$ nanoparticles dispersed in ethylene glycol. The addition of $2 \mathrm{wt} \%$ nanoparticles has led to a $60 \%$ increase in viscosity. On the other hand, Tuteja et al. [28] demonstrated that the addition of polystyrene nanoparticles to linear polystyrene leads to viscosity reduction, but only when the polymer molecules are entangling and confined. The authors confirmed that viscosity reduction can be attributed to an increase in the free volume. Chen et al. [29] observed an increase in matrix chain length $\mathrm{N}$ as a result of loading single-chain nanoparticles (SCNP) into the polystyrene, which amplifies the viscosity reduction effect. They have confirmed that the $\mathrm{N}$-dependent viscosity reduction is associated with friction reduction, and the system with longer polymer chains will have a larger viscosity reduction. A theoretical model was also proposed to justify the viscosity ratio between the polymer/SCNP composite system, with a small SCNP loading, and the pure polymer system measured in an experiment. Changes in rheological properties are not restricted to the two mentioned patterns. An intermediate trend has also been reported for some nanofluids. Motahar et al. [30], have studied the rheological behavior of a system containing the $\mathrm{TiO}_{2}$ nanoparticles dispersed in n-octadecane. They have observed a Newtonian behavior for concentrations lower than 2 wt.\%. By increasing the mass fraction of $\mathrm{TiO}_{2}$ nanoparticles to higher than $2 \mathrm{wt}$. $\%$, the rheological data demonstrate a transition from Newtonian to non-Newtonian behavior.

These earlier examples prove that loading CNTs as nano objects into the liquid can significantly change its rheological properties according to CNT characteristics such as orientation, dimension, aspect ratio, concentration, and surface chemistry [31,32] as well as liquid ones. Hemmat et al. [33] studied the effect of hybrid nanofluids on the rheological behavior of the nanofluid containing multiwall carbon nanotube (MWCNT) and $\mathrm{TiO}_{2}$ nanoparticles and pointed out the significant importance of CNT addition on the rheological properties of the fluid. The nanofluids containing MWCNTs at the solid volume fraction of $0.75 \%$ exhibited an $100 \%$ increase in viscosity. Transition from Newtonian to non-Newtonian pattern as a result of increasing the number of loaded particles was also reported. A larger amount of carbon nanotubes in the nanofluid leads to more pronounced deviation from Newtonian behavior of the nanofluid. Similarly, in another study, Tian et al. [34] incorporated nanoparticles of $\mathrm{CuO} / \mathrm{MWCNTs}$ into the base fluid of mixed waterethylene glycol (EG) in order to study the changes in rheological behavior. They have reported that shortly after the addition of the nanoparticles, the fluid still showed a Newtonian behavior with an increase in viscosity. However, further addition of nanoparticles led to a transition in rheological behavior to the non-Newtonian pattern. Increasing the amount of loaded nanoparticles would have a more intense effect on the rheology of the nanofluid, 
which has been confirmed by Yan et al. [35]. They studied the rheological properties of MWCNTs-ZnO/water-EG system and reported that, increasing the volume fraction of loaded particles, the effect of added particles is intensified, and the non-Newtonian property is more likely to appear. Changes in the rheological behavior of CNT-loaded fluid can be attributed to the percolation of CNT aggregates. In polymer and hydrogel systems containing fillers such as nanoparticles and CNT, the minimum filler concentration that establishes a conductive path of connected particles is considered as percolation threshold [36,37]. These connected particles can affect various properties of the system including thermal and electrical conductivity as well as the rheological properties. Azizi et al. [38] have incorporated MWCNT into a system of polypropylene/polylactic acid (PP/PLA) and studied the changes in electrical and rheological properties after loading various amounts of MWCNT. With the amount of MWCNT reaching $2 \mathrm{wt}$ \% (percolation threshold), the free charge carrier concentration grows dramatically and leads to a significant increase in electrical conductivity. Besides, Nadiv et al. [39] have investigated the integration of CNTs into an epoxy matrix and the changes in rheological properties as a result of forming a percolating network of CNT aggregates. At the percolation threshold, the amount of CNT aggregates exceeds the amount of the individual CNTs, so the aggregate-aggregate interaction hampers their bulk motion as well as the motion of the epoxy molecules within and around them. Therefore, the diffusive motion of epoxy molecules is strongly decreased in the close vicinity of the aggregates, and even at larger distances, leading to an increase in viscosity.

Not only the rheological properties of the sol and subsequent gel but also the mechanical properties and the electrical conductivity of the final materials, e.g., fibers prepared from these sols vary as a result of the increasing CNT load. Research findings confirm that the addition of CNTs into polymeric fibers increases their electrical and thermal conductivities [40]. In fact, the enhanced electrical conductivity of the composite fibers is also a result of the percolation of CNT network. Apart from CNT concentration, their orientation is another important parameter affecting percolation and, in turn, composite fiber electrical conductivity. Drawing fibers can change the orientation and, therefore, the percolation of the fillers [41]. Lu et al. [42] had observed that the electrical conductivity of $\mathrm{CNT}$ / polymeric fibers could be changed by their stretching, for example, experiments with PAN/CNT (4.4 wt.\%) fibers had shown that stretching enables to increase their electrical conductivity from 0.05 to $0.38 \mathrm{~S} / \mathrm{m}$. However, even further stretching has led to a drastic decrease in electrical conductivity of the samples as it leads to breaking contacts between CNTs and, therefore, an interruption of their percolation. The alignment of CNTs may increase or decrease their percolation and thus result in an increase or a decrease in the electrical conductivity of the composites [40].

The rheological behavior of widely used metal alkoxide sols during their gelation has been poorly studied and thus their influence on other properties of the sol-derived fibers remains obscure. The aims of the current study is evaluation of the rheological behavior of MWCNT-loaded titanium alkoxide sols in order to use them as precursors in the preparation of MWCNT/nanoceramic $\mathrm{TiO}_{2}$ composite micro scale fibers. $\mathrm{TiO}_{2}$ is chosen as one of the most used ceramics due to its excellent mechanical and chemical stability, light weight, and promising photovoltaic and catalytic properties [43]. As discussed, the solventless titanium alkoxide fiber precursors are a suitable object for rheological measurements as they undergo gelation very homogeneously, with just a small loss in volume during the gelation. However, for many applications, e.g., electrodes in fuel cells or wear resistant materials, the properties of $\mathrm{TiO}_{2}$ composite materials should still be improved [44].We performed a systematic study of the rheological characteristics of $\mathrm{MWCNT} / \mathrm{TiO}_{2}$ precursors using an extensional rheometry method developed for highly reactive materials. We aimed to improve electrical conductivity of the fibers drawn from the precursor, making them suitable for high technology applications such as optical devices, energy storage, etc. 


\section{Materials and Methods}

\subsection{Preparation of Precursors}

The precursors were synthesized from titanium(IV)propoxide ( $\left.\mathrm{Ti}(\mathrm{OPr})_{4}\right)$ (SigmaAldrich, St. Louis, MO, USA) dissolved in propanol at a room temperature. The reagentgrade propanol (Sigma-Aldrich Comp) was dried with $\mathrm{CaH}_{2}$ and distilled prior to use. The MWCNTs prepared by a catalyzed-chemical-vapor-deposition (CVD) with 10-20 nm diameter and 10-30 $\mu \mathrm{m}$ length were used as purchased from CheapTubes Inc, Cambridgeport, Cambridge, MA, USA.

To initiate the formation of titanium-oxo nanoparticles, propanol, containing $8 \%$ of water, was dropwise added to $10 \mathrm{~g}$ of $\mathrm{Ti}(\mathrm{OPr})_{4}$ to achieve the molar ratio of $\mathrm{R}\left(\mathrm{H}_{2} \mathrm{O} / \mathrm{Ti}(\mathrm{OPr})_{4}\right)=0.5$. Subsequently, MWCNTs (e.g., $0.01 \mathrm{~g}$ ) were added into the solution as a $10 \mathrm{~mL}$ of visually homogeneous solution in dry propanol. Prior to the addition, the nanotube solution was ultrasonicated for $30 \mathrm{~min}$ inside a metric cylinder (e.g., $15 \mathrm{~mL}$ ) by using a Hielscher UP200S (24 kHz and $200 \mathrm{~W}$, Hamm, Germany) apparatus. After mixing, the excess of the solvent was removed from the suspension using a Büchi Rotavapor ${ }^{\circledR}$ R210 (Landsmeer, Netherlands) equipped with a Büchi V700 membrane pump under $65^{\circ} \mathrm{C}$ water bath and 1-5 torr vacuum and an ultrasonic bath (Elmasonic S 30/(H), Singen, Germany, 37kHz and $80 \mathrm{~W}$ ) was used instead of ordinary Büchi heating bath. After removal of the propanol, the visually homogeneous samples with the six different CNT concentrations $(0 ; 0.01 ; 0.02 ; 0.05$; 0.1 and $1 \mathrm{wt} . \%$ ) were obtained for further investigation.

\subsection{Rheological Measurements}

A developed technique for extensional rheometry [44] has been used in the present work. The main advantage of this technique is the possibility to carry out the rheological measurements in the reactor where the high moisture-sensitive fluids were synthesized. The liquid precursor thread was drawn directly in a $100 \mathrm{~mL}$ glass-made reaction bulb. Filament thinning under the combined actions of surface tension, gravity, and rheological effects was monitored through the bulb wall by a high-speed camera (MC1310 Mikrotron $\mathrm{GmbH}$, Unterschleissheim, Germany) with maximum resolution $1280 \times 1024$ pixel at 502 frames per second in the mid-filament region. After the experiment, the obtained video frames were processed using a specially-developed software. As a result, the transient filament profile at a mid-filament area and the evolution of the minimum filament diameter until thread breakup were obtained.

\subsection{Fibers Preparation and Characterization}

After the rheological measurements, the fibers were drawn from the precursor samples by immersing a glass rod, $\sim 5 \mathrm{~mm}$ in diameter, into it and pulling the rod off from the bulb at $\sim 1 \mathrm{~m} / \mathrm{s}$ speed [45]. The surface of the formed liquid precursor threads solidifies immediately in the lab atmosphere (relative humidity $20-50 \%$, temperature $20^{\circ} \mathrm{C}$ ) after the reaction with water vapors in a surrounding atmosphere. This is accompanied by the formation of the bridging -O- bonds between metal-oxo nanoparticles. The prepared fibers were aged then for $24 \mathrm{~h}$ in atmospheric conditions. Multistep thermal treatment up to 200, 300, 400, 500, and $600{ }^{\circ} \mathrm{C}$ was performed to burn out organics and to densify the samples, keeping the samples for $5 \mathrm{~h}$ at each of temperature. Finally, dense fiber samples of 10-50 mm length and 5 to $70 \mu \mathrm{m}$ diameter were obtained.

The transparency and morphology of the annealed fibers were evaluated via an optical microscope and a high-resolution scanning electron microscope (Helios NanoLab 600) equipped with a focused ion beam (FIB). Cutting the fibers along their axes via FIB was necessary to expose aligned CNTs inside the material. The electrical properties of the materials were measured by the 4-point method. The electrical contacts, made of In-Ga alloy, were used between the measuring probes and the fiber-the droplets of alloy, $0.5 \mathrm{~mm}$ in diameter, were placed on parallel gold-coated measuring probes with $1 \mathrm{~mm}$ spacing. The fibers for the measurements were placed perpendicularly across the probes, immersed into the droplets. The resistance was measured using a Keithley, Gorinchem source meter model 
6517A and a Keithley voltmeter model 2400. The fiber diameters, needed in calculations of absolute values of their electrical conductivity, were picked from the obtained SEM images.

\section{Results and Discussions}

\subsection{Preparation of Precursors}

A detailed description of the synthesis of the metal-oxo-propoxide ceramic fiber precursors is detailed elsewhere [46]. Metal alkoxide precursors are highly reactive species, prone to react with water without catalysts. In fact, the reaction results in one-step hydrolysis-condensation transformation [47] associated with the profound restructuring of the molecules, as in the case described below [48,49], for example:

$$
3 \mathrm{Ti}_{2}(\mathrm{OiPr})_{8}+2 \mathrm{H}_{2} \mathrm{O}=2 \mathrm{Ti}_{3} \mathrm{O}(\mathrm{OiPr})_{10}+4 \mathrm{iPrOH}
$$

The hydrolysis of metal alkoxide solutions in (humid) air, without any catalyst, has been denoted as "natural" hydrolysis. It has been shown in many works that hydrolyzed metal alkoxides exist as nanoscopic core-shell structures: sub-crystalline metal-oxo cores (up to 1-2 nm in size), stabilized by an alkoxy layer on their surface. The explanation for the formation of metal-oxo particles is proposed by V. Kessler et al. as micelles templated by self-assembly of ligand (MTSAL) [47]. We have demonstrated earlier that the obtained liquids exhibit non-Newtonian visco-elastic behavior. That behavior, required for their use as fiber drawing dopes, is possible due to the arrangement of primary nanoclusters into secondary elongated units, which undergo sliding when external forces are applied [45].

In this study, the method for the preparation of the fiber precursors was modified in order to incorporate CNTs into the final material. The preliminary $30 \mathrm{~min}$ ultrasonic agitation in a relatively small beaker using the Hielscher UP200S apparatus was necessary to break CNT bundles and agglomerates. Relatively mild sonication conditions ( $80 \mathrm{~W})$ were applied during the solvent removal process. Solvent removal at the same, time with the help of a Buchi roratary evaporator, leads to increased viscosity. At the end of process, the achieved high viscosity 10-10,000 P [20] of drawable fiber precursors prevents MWCNTs from re-aggregating into bundles.

\subsection{The Rheological Properties of the CNT-Doped Metal Alkoxide Precursors}

For the calculation of the rheological parameters from the evolution of the minimum filament diameter, two types of approximations of the experimental data (Figure 1) were applied:

(i) approach for initial and intermediate stages of evolution described by the equation [50]:

$$
\operatorname{Rmin}=A \times \exp (-B \times t)-C \times t+D
$$

(ii) approach at the final stage of the filament evolution described by linear law:

$$
R_{\min }=A \times t+B
$$

where $t$ is time and $A, B, C, D$ are fitting parameters.

Figure 1 gives evidence that Equation (1) approximates experimental data very well only at initial and intermediate times reflecting the visco-elastic regime of filament evolution. Therefore, Equation (1) was used for calculation of the steady-state extensional viscosity $\eta_{E \mu}$ and longest relaxation time $\lambda_{E}$ of liquid:

$$
\begin{aligned}
& \eta_{E \mu}=\sigma / C \\
& \lambda_{E}=1 / 3 B
\end{aligned}
$$

where $\sigma$ is the surface tension. 


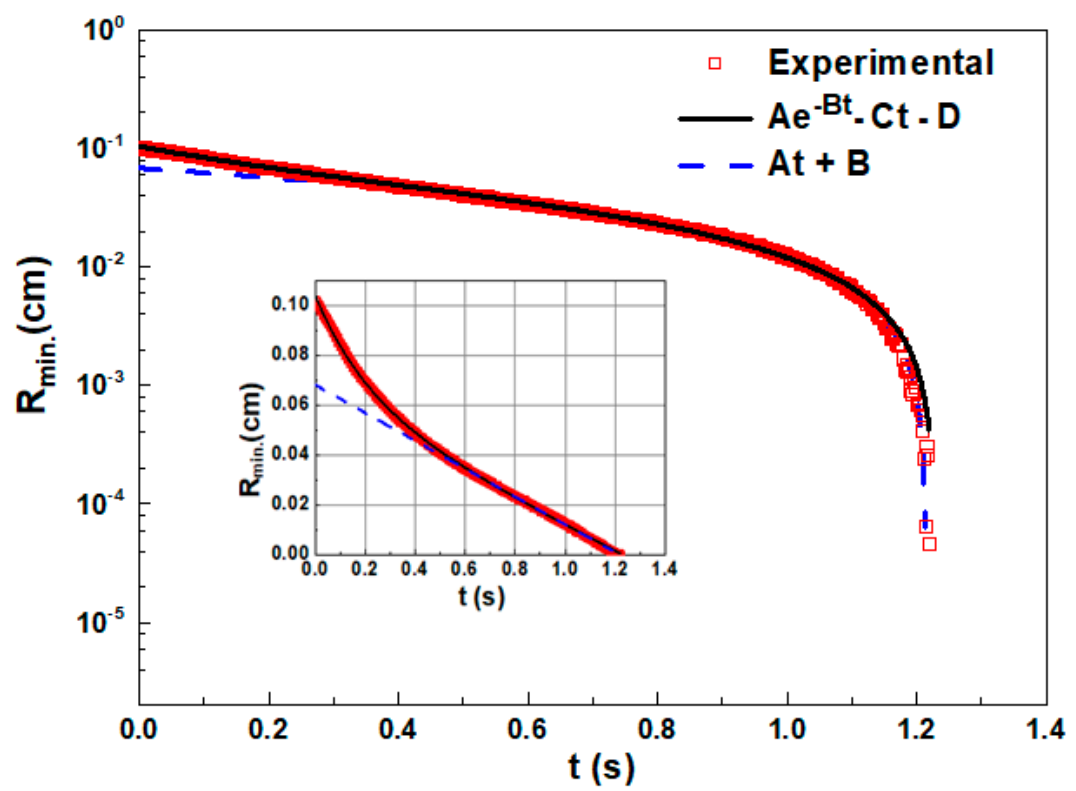

Figure 1. Evolution of the minimal filament diameter with time for CNT-free precursor at the rod elevation of $15 \mathrm{~mm}$. Lines show the fitting of the experimental data by two equations: $R_{\min }=A \times \exp (-B \times t)-C \times t+D$ and $R_{\min }=A \times t+B$. Insertion is in the linear axis for the same data.

At the final stage of filament evolution, just before the break-up, the inner structure of the liquid becomes aligned and elongated. At this stage, the filament diameter varies in time similar to the variation of size known for a Newtonian liquid, i.e., linearly. The approximation of this stage by Equation (2) allows obtaining zero-shear viscosity $\eta_{s}$ of a liquid with a specific inner structure such as aligned CNTs and precursor particles:

$$
\eta_{\mathrm{s}}=-\alpha \times \sigma / \mathrm{A}
$$

where the constant $\alpha=0.0709$.

The measurements were carried out at $15 \mathrm{~mm}$ rod elevation, which defined the length of the filaments. The additional tests were conducted at a $10 \mathrm{~mm}$ rod elevation for a pure sol precursor as well as for the sol precursors with CNTs concentration of 0.05 and $0.1 \mathrm{wt} . \%$ because of too short break-up times of filaments drawn from these samples. It was not possible to get data consistent with the behavior of the sample containing $1 \mathrm{wt} . \% \mathrm{CNTs}$ because of the inhomogeneous nature of the material. The inhomogeneity leads to the quick collapse of the drawn, irregularly-shaped liquid threads before the rod reached the final position needed in measurements. The inhomogeneity could be explained by the bundles and ropes of CNTs, which remain in the material. Alternative explanations for the behavior could be related to the percolation of carbon nanotubes, which critically influence the flowing properties of the precursor at that high CNT concentration.

All the measurements were run at least three times per test condition. Inaccuracy of rheological parameters calculations were no more than $6 \%$ for extensional viscosity, $10 \%$ for zero-shear viscosity, and 30\% for the relaxation time.

Figure 2 shows an unexpected result in the experimental study of the precursors' elongational properties. It can be seen that dispersion of a small amount of CNTs in precursors has led to a dramatic decrease in filament break-up time. The decrease in viscosity and relaxation time for the suspensions containing nanoparticles usually occur if the filler particles are smaller than the radius of gyration. However, in our case, the particle size (the CNTs were 10-20 nm in diameter) is far above the required $2 \mathrm{~nm}$ [46]. Such an effect of CNT's concentration on the rheological parameters could be explained by fluid layers on the surface of dopant particles [51]. The chemical composition of the precursors and their weak interaction with CNTs leads to a reduced viscosity in the fluid layers on the 
particle surface and therefore decreases bulk viscosity. Viscosity reduction as a response to the addition of high aspect ratio solid additives with lowered friction on their surface is in good correlation with earlier results that have shown lowered viscosity of systems containing elongated particles, as reported by Chen et al. [29]. When outer force is applied on such system then the mass of the liquid matrix starts sliding on the surface of elongated filler particles. This results in a decrease of the bulk viscosity of the matter. On the basis of the obtained result, CNTs could be proposed as additives to modify the viscosity of high-viscosity fluids, for example, mineral oils, in order to lower their viscosity.

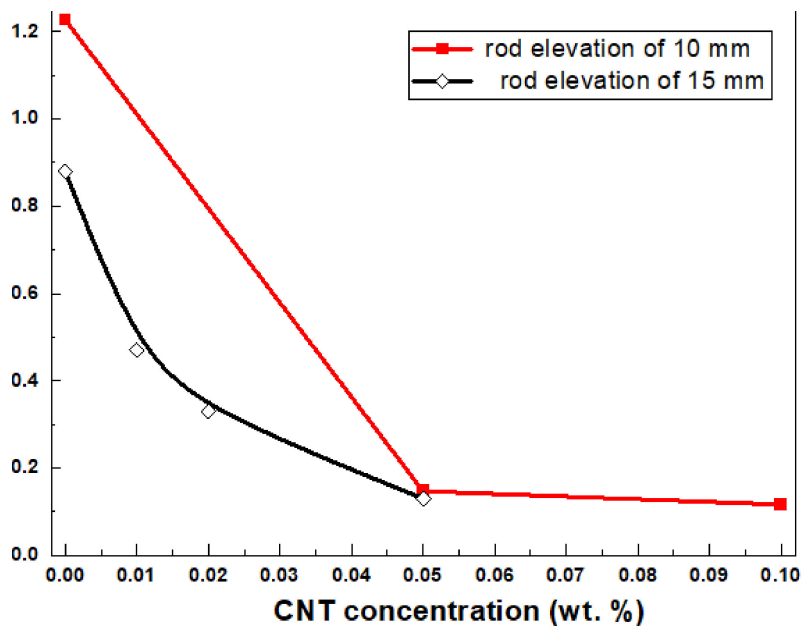

Figure 2. Effect of concentration of CNTs on the filament break-up time $t_{b}$.

It has also been reported earlier that such kind of dependence in the filament breakup time on CNTs concentration in CNT blended epoxy resins could be explained by the formation of CNT clumps-aggregates, ropes, and bundles [52]. However, we have shown that the surface of the produced filaments was smooth and not affected by the clumps at all the concentrations of CNTs (Figure 3), except a heavily loaded sample containing $1 \mathrm{wt} . \%$ of CNTs. The evolution of the minimal filament diameter in time decreases gradually without significant heterogeneities (Figure 4). This indicates the fact that the shorter time of the filament break-up is not related to the non-homogeneous dispersion of CNTs.

(a)
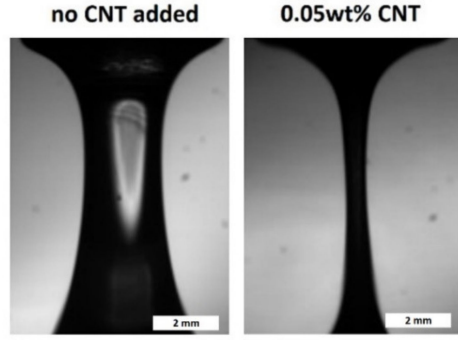

$0.1 w t \%$ CNT

(b)
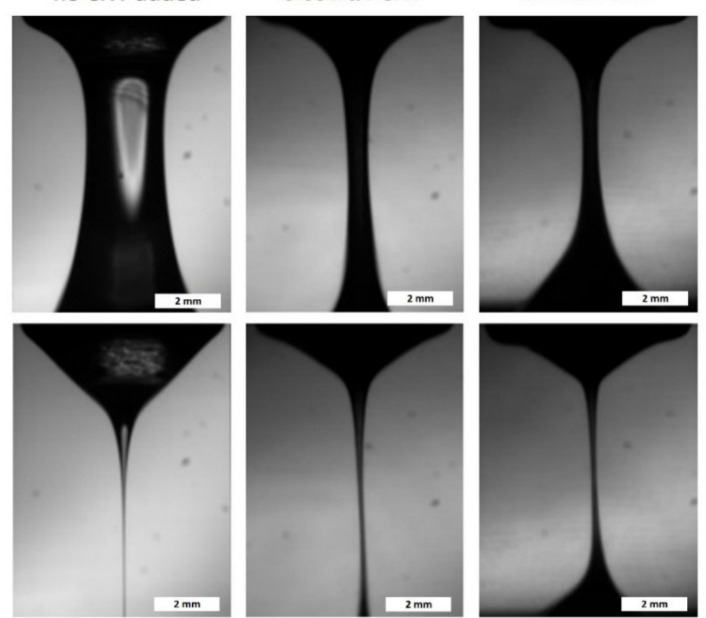

Figure 3. The shapes of the filaments for the liquids without CNT, 0.05 wt.\% CNT, and 0.1 wt.\% CNT (the left, middle and right column, respectively) at 2 times: (a) at $20 \mathrm{~ms}$ after rod cessation; (b) at 20 ms before filament break-up. The lifetimes of the filaments $\left(t_{b}\right)$ were $1.23 \mathrm{~s}, 0.16 \mathrm{~s}$, and $0.1 \mathrm{~s}$, respectively. The rod was elevated for $10 \mathrm{~mm}$. 


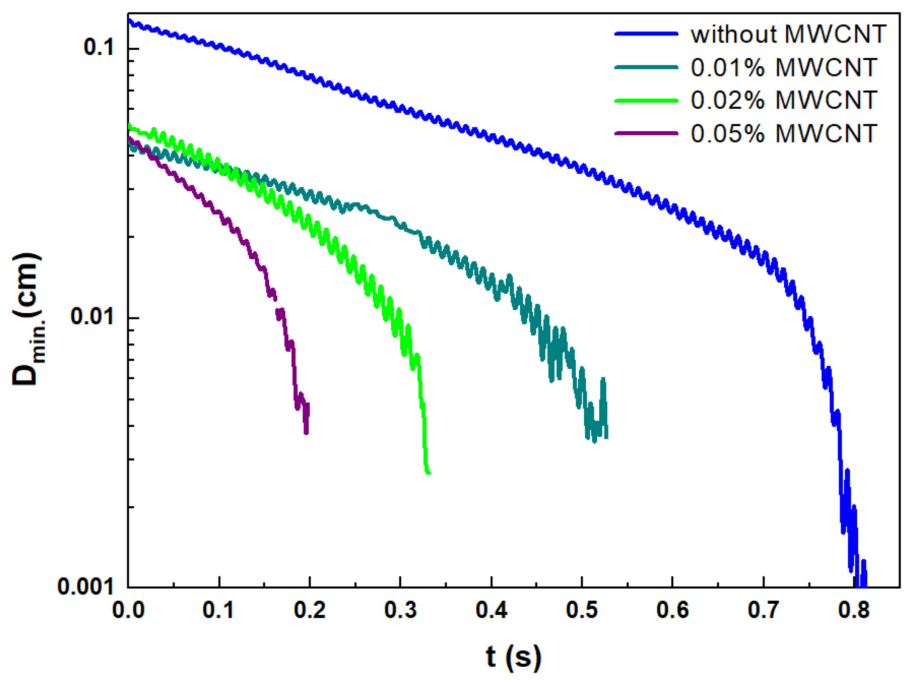

Figure 4. The evolution of the minimal diameter of the pure precursor and precursors with 3 different CNT concentrations: $0.01,0.02,0.05 \mathrm{wt} . \%$. The rod elevation was $15 \mathrm{~mm}$.

The observed effect may be related to the addition of elongated objects such as single MWCNT and their ordered small bundles. To prove this hypothesis, we have studied the influence of CNTs concentration on the rheological parameters of the precursors (Figure 5). It is worth mentioning that the values of zero shear viscosity correspond to the shear viscosity of a liquid with preliminary aligned CNT and particles of the precursor, so that the values were obtained from an approximation of the experimental data with the help of Equation (1). The extensional and zero shear viscosities have the same tendency: a little increase in the case of concentrations equals to $0.01 \mathrm{wt} . \%$, and a strong decrease (by several times) in the concentration of $0.05 \mathrm{wt} . \%$. For larger concentrations ( $0.1 \mathrm{wt} . \%)$ of CNTs, the parameters do not change significantly. The relaxation time decreases with the increase in CNTs content.

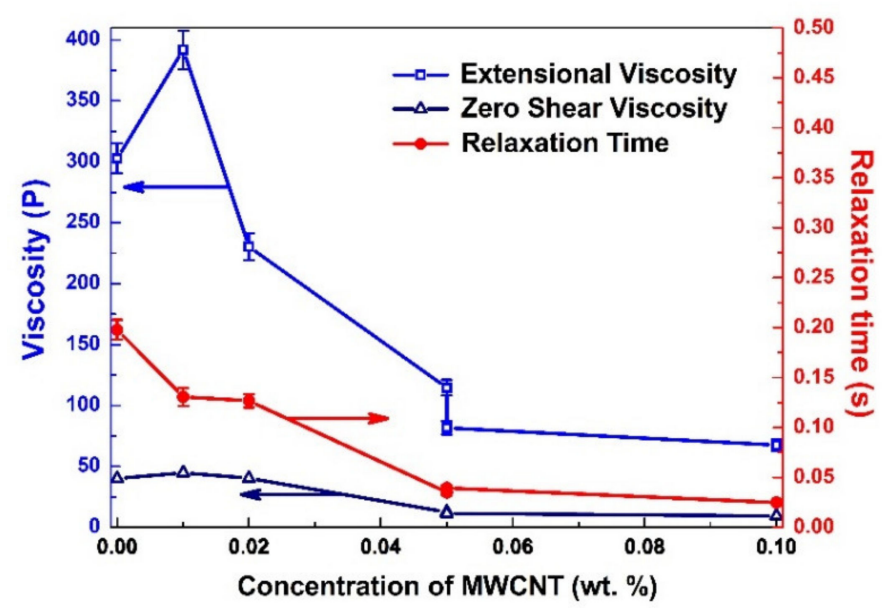

Figure 5. The rheological parameters (steady-state extensional viscosity $\eta_{E \mu}$, zero shear viscosity $\eta_{s}$, and longest relaxation time $\lambda_{E}$ ) as a function of CNT concentration.

\subsection{CNT-Metal Oxide Fiber Preparation and Characterization}

It was possible to draw lengthy fibers with a circular cross-section from all the precursors except the sample with the highest (1 wt.\%) CNT concentration - the sample which also "failed" in rheological characterization. However, it was still possible to prepare some short filaments with a rough surface from that precursor-long enough for further FIB-SEM and conductivity analysis. 
The heat treatment of the as-prepared materials was carried out after their aging in order to determine the temperature required to burn-off organics from oxide material while preserving carbon nanotubes. The thermal behavior of sol-gel prepared fibers is discussed in our earlier study [19], while a comparison of thermal oxidation of amorphous carbon vs. CNTs is discussed in [53]. It was shown also in this work that when using those particular kinds of CNTs purchased from Cheap Tubes Inc. (in the literature, there is significant evidence that the properties of the carbon nanotubes that are provided by different producers vary largely), thermal treatment at $350{ }^{\circ} \mathrm{C}$ in the air can be applied for that purpose. Application of the rather high temperature was possible because of the large diameter of used CNTs such as SWCNTs. As the evaluation of the distribution of CNTs in fiber material with optical microscopy was disturbed heavily by the black color and small diameter of the fibers, SEM imaging was used as the main tool for structural characterization. SEM images revealed that the surface of the fibers was generally smooth, although individual irregularities on the surface could be seen on fibers with CNTs concentrations of $0.1 \mathrm{wt} . \%$. However, it was possible to find smooth areas even on the surface of filaments containing $1 \mathrm{wt} . \%$ of CNTs. As the number of surface irregularities was in correlation to the concentration of CNTs, it can be assumed that irregularities on the surface are most probably caused by CNT ropes and bundles that are still present in the matrix. SEM imaging of the area, cut using FIB, proves clearly that most of the tubes in the material are dispersed as individual tubes, small ropes, or very small bundles (Figure 6).

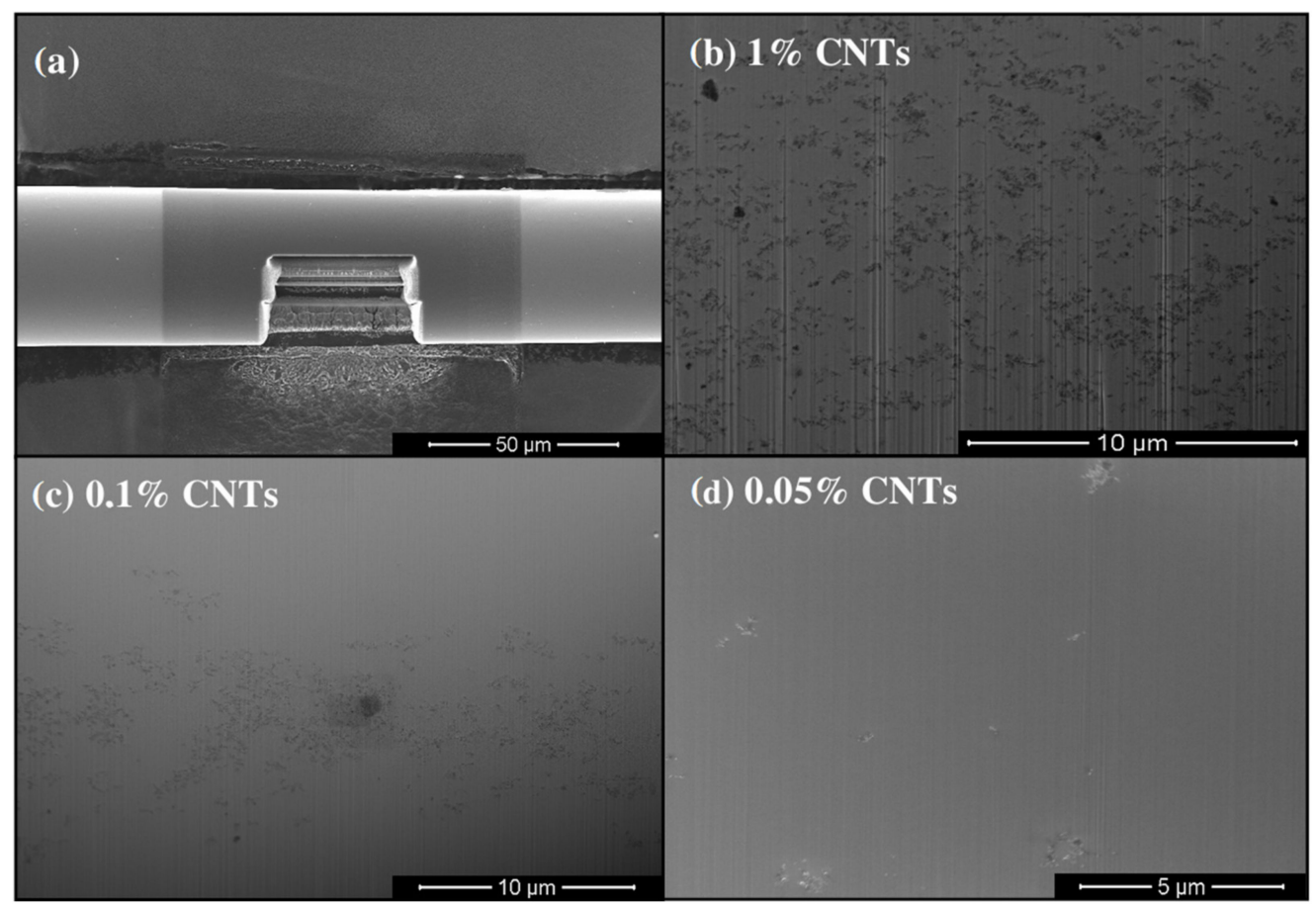

Figure 6. SEM images of (a) a fiber cut by FIB for monitoring of CNTs distribution inside the material; (b-d) images of materials with different MWCNTs concentration.

When 1 wt.\% of CNTs was inserted into the titanium dioxide matrix, the CNT percolation, sufficient for electrical conductivity of the composite material, was detected. The conductivity of the samples containing $1 \mathrm{wt}$ \% of CNTs, heat-treated up to $400{ }^{\circ} \mathrm{C}$, was in the range of $50 \mathrm{~S} / \mathrm{m}$. The latter was at least five orders in magnitude higher value than that of fibers with lower CNT concentration. When the fibers, containing $1 \mathrm{mass} \%$ of $\mathrm{CNTs}$, were heat-treated up to $600{ }^{\circ} \mathrm{C}$ then the conductivity decreased to $10-6 \mathrm{~S} / \mathrm{m}$. Visual observation of the samples under transmitting optical microscopy showed transformation of their color from black (the samples heat-treated at $500{ }^{\circ} \mathrm{C}$ ) to opaque white (heat-treated at $600{ }^{\circ} \mathrm{C}$ ) at the same. Transition of color could be explained by oxidation of CNTs in 
the content. It has been shown earlier that CNTs decompose at thermal treatment up to 375-450 ${ }^{\circ} \mathrm{C}$. Exact decomposition temperature depends on their crystal structure, number of walls and defects. The fact that the samples, heat-treated up to $500{ }^{\circ} \mathrm{C}$, were still black in color demonstrates that $\mathrm{TiO}_{2}$ matrix protects incorporated CNTs against oxygen. The CNT percolation threshold between 0.1 and $1 \mathrm{wt} . \%$ indicates that the used CNT dispersion method was highly effective. For comparison, the CNT network formation in polymerbased composites usually takes place when CNT concentration is in range from 0.5 to $10 \mathrm{wt} . \%$ [54]. The emergence of a CNT percolation network as the response to the increased CNTs concentration can be followed from SEM images of FIB-cut areas of fibers presented in Figure 6. Below 0.05 wt.\%, the CNTs remained scattered inside the matrix, while in the fibers reinforced with $0.1 \mathrm{wt} . \% \mathrm{CNTs}$, individual areas of percolating networks could be seen.

It can be seen from Figure $6 b, c$ that, during the pulling process, CNTs are oriented along the direction of the fiber axis by elongational forces. In addition, it seems from the SEM-FIB analysis that big "loose" bundles are stretched out in the pulling direction. The elongation of particles also demonstrates that highly viscous matrix material solidifying via the formation of bridging - $\mathrm{O}$ - bonds between metal-oxo nanoparticles prohibits to lose of orientation of CNTs. Although in the current study mechanical properties of the composites were not measured, it is known from the experiments with polymer/CNT fibers that the orientation of the carbon nanotubes enhances the overall mechanical strength of the material [55].

\section{Conclusions}

Ti-oxo-propoxide precursors were prepared from Ti-propoxide as a result of the reaction with water. CNTs were ultrasonicated in propanol and added to the precursors in order to obtain suitable materials for the fabrication of $\mathrm{CNT}-\mathrm{TiO}_{2}$ composite fibers. The fibers were drawn directly from the precursors, aged, and thermally treated. As one of the most important parameters of the fiber precursor material, the viscoelastic properties of the precursors were studied prior to fiber processing. Rheological studies carried out by applying unique elongational rheometry - a novel set-up proposed earlier-demonstrated a decrease in elongational viscosity and relaxation time with an increase in CNT content at low concentrations (less than $0.1 \mathrm{wt.} \%$ ). The zero-shear viscosity of the pre-aligned CNTdoped precursors with increasing CNTs content was also decreased. Careful heat-treatment of the materials at $350{ }^{\circ} \mathrm{C}$ resulted in the oxidation of organic additives and amorphous carbon from the final CNT-doped $\mathrm{TiO}_{2}$ ceramic materials. The percolation of CNTs for good electrical conductivity, $50 \mathrm{~S} / \mathrm{m}$, was achieved by adding $1 \mathrm{wt}$ \% of CNTs to the precursor materials. The percolation-based conductivity mechanism was supported by the fact that heat-treatment up to $500{ }^{\circ} \mathrm{C}$ caused six orders of magnitude drop-down in conductivity down to as low as $10-6 \mathrm{~S} / \mathrm{m}$ as a result of the oxidation of the carbon nanotube network.

Author Contributions: Conceptualization, T.T. and M.H.; Data curation, M.P.; Methodology, M.H.; Writing-original draft, T.T., M.A. and A.V.; Writing-review \& editing, M.A., A.V. and I.H. All authors have read and agreed to the published version of the manuscript.

Funding: This work has been supported by the Estonian Research Council research targeted projects (PRG643), the the ERDF funding in Estonia granted to the Centre of Excellence TK141 "Advanced materials and high-technology devices for sustainable energetics, sensorics and nanoelectronics (HiTechDevices)" (grant no. 2014-2020.4.01.15-0011).

Institutional Review Board Statement: Not applicable.

Informed Consent Statement: Not applicable.

Data Availability Statement: Some or all data, models, or code that support the findings of this study are available from the corresponding author upon reasonable request.

Conflicts of Interest: The authors declare no conflict of interest. 


\section{References}

1. Liu, C.; Cheng, H.-M. Carbon nanotubes: Controlled growth and application. Mater. Today 2013, 16, 19-28. [CrossRef]

2. Gupta, N.; Gupta, S.M.; Sharma, S.K. Carbon nanotubes: Synthesis, properties and engineering applications. Carbon Lett. 2019, 29, 419-447. [CrossRef]

3. Lan, Y.; Wang, Y.; Ren, Z.F. Physics and applications of aligned carbon nanotubes. Adv. Phys. 2011, 60, 553-678. [CrossRef]

4. Eatemadi, A.; Daraee, H.; Karimkhanloo, H.; Kouhi, M.; Zarghami, N.; Akbarzadeh, A.; Abasi, M.; Hanifehpour, Y.; Joo, S.W. Carbon nanotubes: Properties, synthesis, purification, and medical applications. Nanoscale Res. Lett. 2014, 9, 393. [CrossRef]

5. Ahmad, K.; Pan, W. Microstructure-toughening relation in alumina based multiwall carbon nanotube ceramic composites. J. Eur. Ceram. Soc. 2015, 35, 663-671. [CrossRef]

6. Xin, X.; Zhou, X.; Wu, J.; Yao, X.; Liu, Z. Scalable Synthesis of $\mathrm{TiO}_{2} /$ Graphene Nanostructured Composite with High-Rate Performance for Lithium Ion Batteries. ACS Nano 2012, 6, 11035-11043. [CrossRef]

7. Kazazi, M.; Zafar, Z.A.; Delshad, M.; Cervenka, J.; Chen, C. $\mathrm{TiO}_{2} / \mathrm{CNT}$ nanocomposite as an improved anode material for aqueous rechargeable aluminum batteries. Solid State Ionics 2018, 320, 64-69. [CrossRef]

8. Cho, J.; Boccaccini, A.R.; Shaffer, M.S.P. Ceramic matrix composites containing carbon nanotubes. J. Mater. Sci. 2009, 44, 1934-1951 [CrossRef]

9. He, C.; Zhao, N.; Shi, C.; Song, S. Mechanical properties and microstructures of carbon nanotube-reinforced Al matrix composite fabricated by in situ chemical vapor deposition. J. Alloys Compd. 2009, 487, 258-262. [CrossRef]

10. Leonov, A.A.; Khasanov, A.O.; Danchenko, V.A.; Khasanov, O.L. Spark plasma sintering of ceramic matrix composite based on alumina, reinforced by carbon nanotubes. IOP Conf. Ser. Mater. Sci. Eng. 2017, 286, 012034. [CrossRef]

11. Candelario, V.M.; Moreno, R.; Shen, Z.; Ortiz, A.L. Aqueous colloidal processing of nano-SiC and its nano-Y3Al5O12 liquid-phase sintering additives with carbon nanotubes. J. Eur. Ceram. Soc. 2015, 35, 3363-3368. [CrossRef]

12. Rehman, M.A.U.; Chen, Q.; Braem, A.; Shaffer, M.S.P.; Boccaccini, A.R. Electrophoretic deposition of carbon nanotubes: Recent progress and remaining challenges. Int. Mater. Rev. 2020, 66, 1-30. [CrossRef]

13. Esquivias, L.; Rivero-Antúnez, P.; Zamora-Ledezma, C.; Domínguez-Rodríguez, A.; Morales-Flórez, V. Intragranular carbon nanotubes in alumina-based composites for reinforced ceramics. J. Sol Gel Sci. Technol. 2018, 90, 162-171. [CrossRef]

14. Satapathy, S.; Prabakaran, P.; Prasad, E.; Satapathy, S. Augmenting Photoinduced Charge Transport in a Single-Component Gel System: Controlled In Situ Gel-Crystal Transformation at Room Temperature. Chem. A Eur. J. 2018, 24, 6217-6230. [CrossRef] [PubMed]

15. Satapathy, S.; Prasad, E. Charge Transfer Modulated Self-Assembly in Poly(aryl ether) Dendron Derivatives with Improved Stability and Transport Characteristics. ACS Appl. Mater. Interfaces 2016, 8, 26176-26189. [CrossRef] [PubMed]

16. Joly, C.; Goizet, S.; Schrotter, J.; Sanchez-Marcano, J.; Escoubes, M. Sol-gel polyimide-silica composite membrane: Gas transport properties. J. Membr. Sci. 1997, 130, 63-74. [CrossRef]

17. Zapata-Solvas, E.; García, D.G.; Dominguez-Rodriguez, A. Towards physical properties tailoring of carbon nanotubes-reinforced ceramic matrix composites. J. Eur. Ceram. Soc. 2012, 32, 3001-3020. [CrossRef]

18. Sakka, S.; Yoko, T. Fibers from gels. J. Non Cryst. Solids 1992, 147-148, 394-403. [CrossRef]

19. Part, M.; Hanschmidt, K.; Jõgi, J.; Rauwel, E.; Seisenbaeva, G.A.; Kessler, V.G.; Tätte, T. Study of the curing mechanism of metal alkoxide liquid threads for the synthesis of metal oxide fibers or microtubes. RSC Adv. 2014, 4, 12545-12554. [CrossRef]

20. Tätte, T.; Part, M.; Talviste, R.; Hanschmidt, K.; Utt, K.; Mäeorg, U.; Jõgi, I.; Kiisk, V.; Mändar, H.; Nurk, G.; et al. Yttria stabilized zirconia microtubes for microfluidics under extreme conditions. RSC Adv. 2014, 4, 17413-17419. [CrossRef]

21. Nadiv, R.; Vasilyev, G.; Shtein, M.; Peled, A.; Zussman, E.; Regev, O. The multiple roles of a dispersant in nanocomposite systems. Compos. Sci. Technol. 2016, 133, 192-199. [CrossRef]

22. Nadiv, R.; Shachar, G.; Peretz-Damari, S.; Varenik, M.; Levy, I.; Buzaglo, M.; Ruse, E.; Regev, O. Performance of nano-carbon loaded polymer composites: Dimensionality matters. Carbon 2018, 126, 410-418. [CrossRef]

23. Katepalli, H.; John, V.T.; Tripathi, A.; Bose, A. Microstructure and rheology of particle stabilized emulsions: Effects of particle shape and inter-particle interactions. J. Colloid Interface Sci. 2017, 485, 11-17. [CrossRef]

24. Gossard, A.; Frances, F.; Aloin, C. Rheological properties of $\mathrm{TiO}_{2}$ suspensions varied by shifting the electrostatic inter-particle interactions with an organic co-solvent. Colloids Surf. A Physicochem. Eng. Asp. 2017, 522, 425-432. [CrossRef]

25. Morris, J.F. Toward a fluid mechanics of suspensions. Phys. Rev. Fluids 2020, 5, 110519. [CrossRef]

26. Kawaguchi, M. Dispersion stability and rheological properties of silica suspensions in aqueous solutions. Adv. Colloid Interface Sci. 2020, 284, 102248. [CrossRef]

27. Esfe, M.H.; Saedodin, S.; Asadi, A.; Karimipour, A. Thermal conductivity and viscosity of $\mathrm{Mg}(\mathrm{OH})_{2}$-ethylene glycol nanofluids. J. Therm. Anal. 2015, 120, 1145-1149. [CrossRef]

28. Tuteja, A.; Duxbury, P.M.; Mackay, M.E. Multifunctional Nanocomposites with Reduced Viscosity. Macromolecules 2007, 40, 9427-9434. [CrossRef]

29. Chen, T.; Zhao, H.-Y.; Shi, R.; Lin, W.-F.; Jia, X.-M.; Qian, H.-J.; Lu, Z.-Y.; Zhang, X.-X.; Li, Y.-K.; Sun, Z.-Y. An unexpected $\mathrm{N}$-dependence in the viscosity reduction in all-polymer nanocomposite. Nat. Commun. 2019, 10, 5552. [CrossRef]

30. Motahar, S.; Nikkam, N.; Alemrajabi, A.A.; Khodabandeh, R.; Toprak, M.S.; Muhammed, M. Experimental investigation on thermal and rheological properties of n-octadecane with dispersed $\mathrm{TiO}_{2}$ nanoparticles. Int. Commun. Heat Mass Transf. 2014, 59, 68-74. [CrossRef] 
31. Advani, S.G.; Fan, Z. Effect of Dispersion State on the Rheology of Multi-walled Carbon nanotube Suspensions in Shear Flow. AIP Conf. Proc. 2004, 712, 1619-1623. [CrossRef]

32. Kharchenko, S.B.; Douglas, J.F.; Obrzut, J.; Grulke, E.A.; Migler, K. Flow-induced properties of nanotube-filled polymer materials. Nat. Mater. 2004, 3, 564-568. [CrossRef] [PubMed]

33. Esfe, M.H.; Arani, A.A.A.; Madadi, M.R.; Alirezaie, A. A study on rheological characteristics of hybrid nano-lubricants containing MWCNT-TiO 2 nanoparticles. J. Mol. Liq. 2018, 260, 229-236. [CrossRef]

34. Tian, Z.; Rostami, S.; Taherialekouhi, R.; Karimipour, A.; Moradikazerouni, A.; Yarmand, H.; Zulkifli, N.W.B.M. Prediction of rheological behavior of a new hybrid nanofluid consists of copper oxide and multi wall carbon nanotubes suspended in a mixture of water and ethylene glycol using curve-fitting on experimental data. Phys. A Stat. Mech. Appl. 2020, 549, 124101. [CrossRef]

35. Yan, S.-R.; Toghraie, D.; Abdulkareem, L.A.; Alizadeh, A.; Barnoon, P.; Afrand, M. The rheological behavior of MWCNTs$\mathrm{ZnO} /$ Water-Ethylene glycol hybrid non-Newtonian nanofluid by using of an experimental investigation. J. Mater. Res. Technol. 2020, 9, 8401-8406. [CrossRef]

36. Chanklin, W.; Laowongkotr, J.; Chibante, L.F. Electrical property validation of percolation modeling in different polymer structures of carbon-based nanocomposites. Mater. Today Commun. 2018, 17, 153-160. [CrossRef]

37. Warren, H.; Gately, R.D.; O’Brien, P.; Gorkin, R., III; Panhuis, M.I.H. Electrical conductivity, impedance, and percolation behavior of carbon nanofiber and carbon nanotube containing gellan gum hydrogels. J. Polym. Sci. Part B Polym. Phys. 2014, 52, 864-871. [CrossRef]

38. Azizi, S.; Azizi, M.; Sabetzadeh, M. The Role of Multiwalled Carbon Nanotubes in the Mechanical, Thermal, Rheological, and Electrical Properties of PP/PLA/MWCNTs Nanocomposites. J. Compos. Sci. 2019, 3, 64. [CrossRef]

39. Nadiv, R.; Fernandes, R.M.; Ochbaum, G.; Dai, J.; Buzaglo, M.; Varenik, M.; Biton, R.; Furó, I.; Regev, O. Polymer nanocomposites: Insights on rheology, percolation and molecular mobility. Polymer 2018, 153, 52-60. [CrossRef]

40. Liu, Y.; Kumar, S. Polymer/Carbon Nanotube Nano Composite Fibers-A Review. ACS Appl. Mater. Interfaces 2014, 6, 6069-6087. [CrossRef] [PubMed]

41. Dabrowska, I.; Fambri, L.; Pegoretti, A.; Slouf, M.; Vackova, T.; Kolarik, J. Spinning, drawing and physical properties of polypropylene nanocomposite fibers with fumed nanosilica. Express Polym. Lett. 2015, 9, 277-290. [CrossRef]

42. Lu, M.; Gulgunje, P.V.; Arias-Monje, P.J.; Luo, J.; Ramachandran, J.; Sahoo, Y.; Agarwal, S.; Kumar, S. Structure, properties, and applications of polyacrylonitrile/carbon nanotube (CNT) fibers at low CNT loading. Polym. Eng. Sci. 2020, 60, 2143-2151. [CrossRef]

43. Basu, B.; Balani, K. Advanced Structural Ceramics; John Wiley \& Sons: Hoboken, NJ, USA, 2011.

44. Hussainov, M.; Tätte, T.; Hussainova, I. Technique for extensional rheology characterization of highly reactive viscoelastic liquids. Rheol. Acta 2012, 51, 729-742. [CrossRef]

45. Tatte, T.; Hussainov, M.; Paalo, M.; Part, M.; Talviste, R.; Kiisk, V.; Mändar, H.; Põhako, K.; Pehk, T.; Reivelt, K.; et al. Alkoxidebased precursors for direct drawing of metal oxide micro- and nanofibres. Sci. Technol. Adv. Mater. 2011, 12, 34412. [CrossRef]

46. Kisand, V.; Shulga, J.; Tätte, T.; Visk, U.; Natali, M.; Mistura, G.; Paalo, M.; Lobjakas, M.; Kink, I. Preparation of structured sol-gel films using tape casting method. Mater. Sci. Eng. B 2007, 137, 162-165. [CrossRef]

47. Kessler, V.G. The chemistry behind the sol-gel synthesis of complex oxide nanoparticles for bio-imaging applications. J. Sol-Gel Sci. Technol. 2009, 51, 264-271. [CrossRef]

48. Spijksma, G.I.; Seisenbaeva, G.A.; Fischer, A.; Bouwmeester, H.J.M.; Blank, D.H.A.; Kessler, V.G. The molecular composition of non-modified and acac-modified propoxide and butoxide precursors of zirconium and hafnium dioxides. J. Sol-Gel Sci. Technol. 2009, 51, 10-22. [CrossRef]

49. Senouci, A.; Yaakoub, M.; Huguenard, C.; Henry, M. Molecular templating using titanium(iv)(oxo)alkoxides and titanium(iv)(oxo)aryloxides. J. Mater. Chem. 2004, 14, 3215-3230. [CrossRef]

50. Anna, S.; McKinley, G. Elasto-capillary thinning and breakup of model elastic liquids. J. Rheol. 2001, 45, 115-138. [CrossRef]

51. Pötschke, P.; Fornes, T.; Paul, D. Rheological behavior of multiwalled carbon nanotube/polycarbonate composites. Polymer 2002, 43, 3247-3255. [CrossRef]

52. Miyazono, K.; Kagarise, C.D.; Koelling, K.W.; Mahboob, M.; Bechtel, S.E. Shear and extensional rheology and flow-induced orientation of carbon nanofiber/polystyrene melt composites. J. Appl. Polym. Sci. 2011, 119, 1940-1951. [CrossRef]

53. Brukh, R.; Mitra, S. Kinetics of carbon nanotubeoxidation. J. Mater. Chem. 2007, 17, 619-623. [CrossRef]

54. Du, J.-H.; Bai, J.; Cheng, H.-M. The present status and key problems of carbon nanotube based polymer composites. Express Polym. Lett. 2007, 1, 253-273. [CrossRef]

55. Spitalsky, Z.; Tasis, D.; Papagelis, K.; Galiotis, C. Carbon nanotube-polymer composites: Chemistry, processing, mechanical and electrical properties. Prog. Polym. Sci. 2010, 35, 357-401. [CrossRef] 